\title{
Análise do gerenciamento de resíduos sólidos urbanos através de indicadores de sustentabilidade no município de Uiraúna-PB
}

\author{
Erverton Cezário de Freitas \& José Deomar de Souza Barros
}

Universidade Federal de Campina Grande, Centro de Formação de Professores, Unidade Acadêmica de Ciências Exatas e da Natureza, Rua Sérgio Moreira de Figueiredo, Casas Populares 58900-000, Cajazeiras, Paraíba, Brasil. E-mail: deomarbarros@gmail.com

Freitas E.C. \& Barros J.D.S. (2021) Análise do gerenciamento de resíduos sólidos urbanos através de indicadores de sustentabilidade no município de Uiraúna-PB. Pesquisa e Ensino em Ciências Exatas e da Natureza, 5: e1803. http://dx.doi.org/10.29215/pecen.v5i0.1803

Editora acadêmica: Jacqueline Santos Silva Cavalcanti. Recebido: 14 abril 2021. Aceito: 01 setembro 2021. Publicado: 04 outubro 2021.

Resumo: Com a expansão das cidades e o crescimento populacional possibilitou o consumo exagerado de produtos industrializados aumentando assim seu descarte de modo acelerado. Tendo em vista o avanço das tecnologias com o passar dos anos, os produtos foram mudando sua composição de modo que seu descarte em locais inadequados permitiu a contaminação do meio ambiente. Dentro desse contexto, a realidade de alguns municípios brasileiros, principalmente nas cidades do interior do país, ainda descartam seus resíduos de forma inadequada provocando impactos ambientais e perda da qualidade de vida da população, constituindo assim um dos principais problemas a serem solucionados atualmente. Neste sentido, vários estudos vêm sendo apresentados com relação a essa problemática buscando melhorias e desenvolvendo estratégias que possam mitigar ou na melhor situação para resolução da problemática do gerenciamento de resíduos sólidos urbanos. Tendo-se em vista essa realidade, a presente pesquisa teve como objetivo analisar o gerenciamento de resíduos sólidos por meio de indicadores de sustentabilidade na Cidade de Uiraúna-PB. O estudo em questão contém abordagens tanto quantitativas como qualitativas sobre a disposição desses rejeitos. A metodologia empregada para o desenvolvimento da pesquisa foi baseada em Castro (2016) seguindo o modelo adaptado por Bento (2020) de modo que os indicadores foram convertidos de qualitativos para quantitativos para que ocorra uma melhor compreensão dos dados coletados. As informações foram coletadas através da aplicação de questionário a diferentes grupos de atores sociais residentes no município de Uiraúna-PB. Após avaliação dos dados, verificou-se que dentre os trinta e sete (37) indicadores avaliados, vinte (20) foram considerados favoráveis e treze (13) desfavoráveis, porém é importante ressaltar que a maioria dos indicadores que foram destacados como favoráveis são referentes a perguntas de conhecimento e opinião sobre o manejo, coleta, destinação final adequada dos resíduos e de como esses resíduos sólidos urbanos (RSU) poderiam afetar a população quando não acondicionado de forma regular. Enquanto que as desfavoráveis estavam voltadas para questões mais relevantes como inexistência de local apropriado para o descarte final de resíduos, vazadouros a céu aberto próximo as residências, contaminação de populares através desses resíduos. Dentro dessa perspectiva o estudo destacou a urgência que o município de Uiraúna-PB apresenta para que haja mudanças em seu gerenciamento de resíduos sólidos urbanos.

Palavras chave: Crescimento populacional, produtos industrializados, prejuízo ambiental, indicadores.

Analysis of urban solid waste management using sustainability indicators in the Municipality of Uiraúna, State of Paraíba, Brazil

Abstract: The expansion of cities and population growth has led to the unbridled consumption of industrialized products, accompanied by an accelerated increase in the discarding of these products. Advances in technologies over the years have brought changes in the composition of products, the 
discarding of which in inadequate locations leads to the contamination of the environment. Many Brazilian cities, especially those distant from major metropolises, continue to discard waste inadequately, causing environmental impact and the loss of quality of life of the population, which currently constitutes one of the major problems that require a solution. Several studies have addressed this problem in the search for improvements and the development of strategies that solve or at least mitigate the problems of urban solid waste management. The aim of the present study was to analyze urban solid waste management using sustainability indicators in the municipality of Uiraúna in the state of Paraíba, Brazil. Quantitative and qualitative approaches were used to address the situation of this waste. The method employed for the development of the study was based on Castro (2016) following the model adapted by Bento (2020). Thus, qualitative indicators were converted into quantitative indicators to facilitate the understanding of the data. Data was collected with the aid of a questionnaire administered to groups of different social actors residing in the municipality. The analysis of the data revealed that 20 of the 37 indicators evaluated were considered favorable and 13 were considered unfavorable. However, the majority of indicators considered favorable referred to questions addressing the respondents' knowledge and opinions regarding the management, collection and adequate final destination of waste and how urban solid waste could affect the population if not discarded appropriately. In contrast, the unfavorable indictors referred to more relevant issues, such as the inexistence of an appropriate location for the final discarding of waste, open-air dumps near residences and the contamination of the population through this waste. This study highlights an urgent need for the municipality of Uiraúna, Brazil, to make appropriate changes in its management of urban solid waste.

Key words: Population growth, industrialized products, environmental harm, indicators.

\section{Introdução}

De acordo com a Política Nacional dos Resíduos Sólidos - PNRS, caracteriza-se como resíduos sólidos, todo material, substância, objeto que pode ser desprezado, sendo originado da ação humana em conjunto com a sociedade, cujo destino final procede-se ao sólido ou semissólido, bem como gases armazenados em recipientes e líquidos, das quais as especificidades tornem por fim inviável o descarte em rede pública tais como, esgotos ou em corpos d’água, ou que careçam de soluções técnicas e econômicas tendo em vista a melhor tecnologia assim disponível (Brasil 2010).

Desde os períodos mais remotos, os materiais já estavam presentes na história da humanidade, e sua relação com o manejo dos mesmos auxiliavam nas suas tarefas do cotidiano, onde pode ser evidenciado em alguns períodos da antiguidade como: idade da pedra, idade da pedra lascada, idade do bronze, idade do ferro (Mancini et al. 2012). Com a evolução das tecnologias, o homem passou a ter a sua disposição os mais diferentes materiais, que possibilitou o avanço cientifico e permitiu o desenvolvimento de novas tecnologias.

A problemática relacionada aos resíduos sólidos teve agravo a partir da revolução industrial, onde o mesmo deixou de ser produzido em pequena quantidade para ser produzido em grande quantidade, permitindo a soma ou acúmulo de resíduos nas áreas urbanas (Barbosa 2008). O mesmo também ressalta a produção desenfreada de resíduos sólidos tornando-se assim um dos grandes desafios a ser enfrentado pela sociedade atual.

Com o crescente aumento populacional, a economia em ascensão, a ligeira urbanização e a alta nos padrões de vida da comunidade apressaram a taxa de produção desses resíduos (Berticelli et al. 2017). Gouveia (2012) aponta que os resíduos sólidos, devido ao seu aumento durante os últimos anos, tiveram sua composição modificada, começando a apresentar elementos sintéticos e altamente nocivos à saúde humana e ao meio ambiente, sendo constatado que isso se deu também devido ao avanço das tecnologias agregado ao cotidiano.

De acordo com Leite \& Barros (2019), o aumento descontrolado da população a nível global está também relacionado aos impactos ambientais, pois a população em geral tende a manter um modo de vida consumista, desencadeando um resultado direto na exploração desordenada dos recursos naturais, permitindo aumento significante dos níveis de poluição, possibilitando também percas ambientais imensuráveis sendo caracterizada pela alta produção de resíduos. 
Berticelli et al. (2017) apontam os grandes desafios que os municípios enfrentam com relação a essa problemática que são os resíduos sólidos, onde a instituição pública tem como obrigação propiciar estratégias ou medidas que sejam eficazes para mitigar os efeitos provocados por seu acúmulo. Infelizmente, a grande maioria dos municípios continua com técnicas e práticas inapropriadas de disposição desses resíduos.

Neste aspecto, os indicadores de sustentabilidade podem se mostrar de grande importância, tendo-se em vista que os mesmos podem facilitar o acesso a informações técnicas e científicas, no qual sua principal função é organizar dados de modo que fiquem de fácil entendimento (Pereira et al. 2018). Conforme Ferreira \& Barros (2021), os indicadores de sustentabilidade se constituem instrumentos relevantes na análise de dados relativos à gestão e gerenciamento dos RSU, possibilitando a criação de estratégias e métodos para cada situação e suas especificidades.

Assim, a presente pesquisa procura contribuir e buscar melhorias para gestão de resíduos tendo-se em vista o quadro atual, utilizando os indicadores de sustentabilidade para verificar a qualidade e seus impactos ocasionados por esses resíduos no Município de Uiraúna-PB; e teve por objetivo analisar o gerenciamento de resíduos sólidos por meio de indicadores de sustentabilidade na Cidade de Uiraúna-PB.

\section{Metodologia}

\section{Delimitação e caracterização da área de estudo}

A pesquisa foi realizada no município de Uiraúna - $\mathrm{PB}$, no período de 11 de abril a 19 de setembro de 2019. O município de Uiraúna - PB está localizado no Semiárido nordestino brasileiro, a Oeste do Estado da Paraíba, na Microrregião de Cajazeiras que forma parte da Mesorregião do Alto Sertão Paraibano. Tendo seus limites a norte com os municípios potiguares de Luís Gomes e Paraná; a (Sul), a leste e oeste com os seguintes municípios paraibanos: São João do Rio do Peixe, a (Sul); Vieiropólis, a (Leste), Joca Claudino e Poço de José de Moura a Oeste (Figura 1) (Ferreira \& Barros 2021).

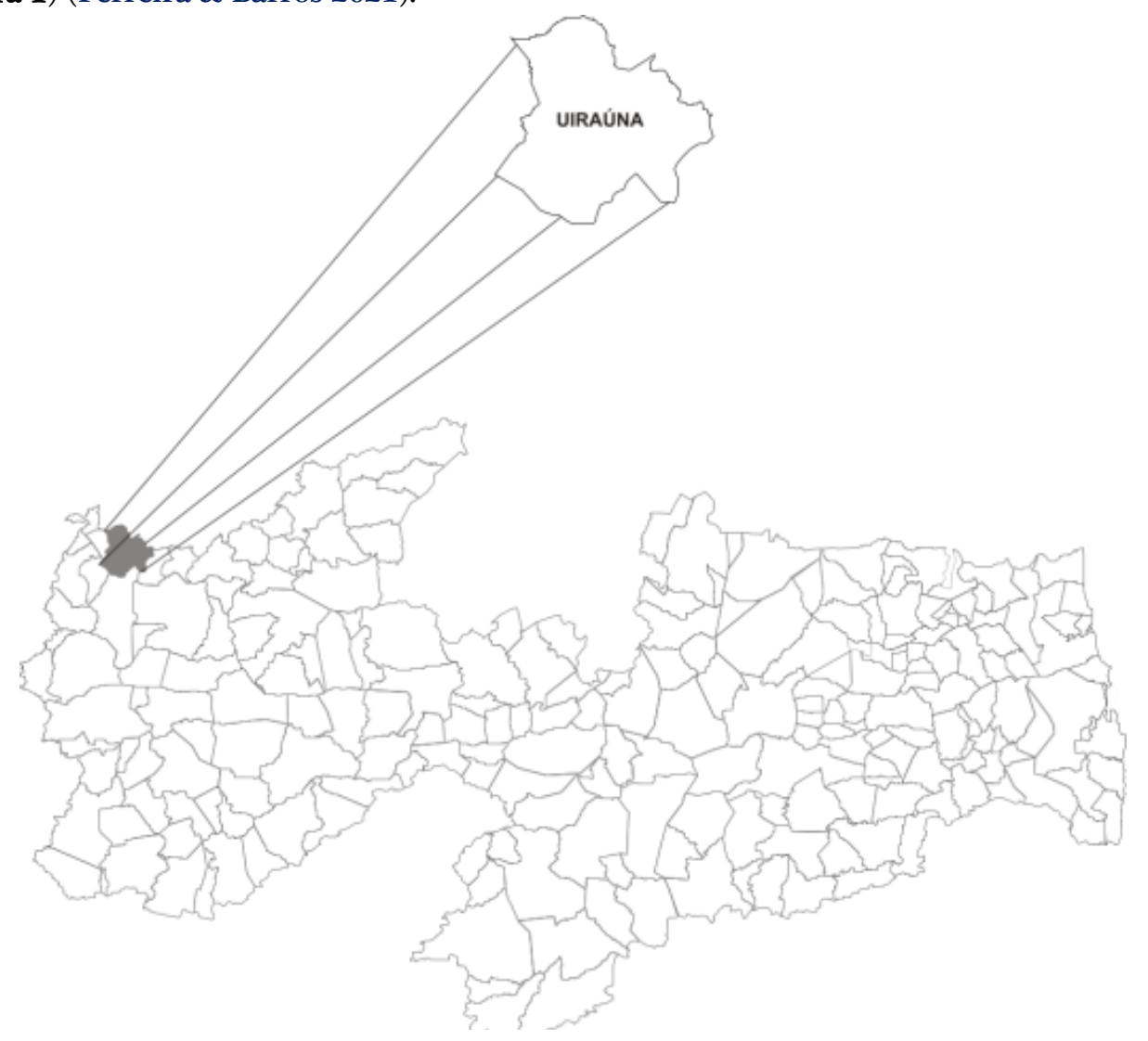

Figura 1. Localização do Município de Uiraúna-PB no Território Paraibano. Fonte: Ferreira \& Barros (2021). 
Tem sua posição demarcada pelas coordenadas geográficas com latitude 06 $31^{\circ} 03^{\prime \prime} \mathrm{S}$ e Longitude $38^{\circ} 24^{\prime} 28^{\prime \prime} \mathrm{O}$, tem Altitude 301 metros em relação ao nível do mar. Seu território possui $293.182 \mathrm{~km}^{2}$ e conta com uma população de 15.300 habitantes (Ferreira \& Barros 2021).

\section{Classificação da pesquisa}

Do ponto de vista de sua natureza, a pesquisa foi caracterizada como pesquisa aplicada, no qual, conforme Zanella (2013), o mesmo teve como objetivo gerar conhecimentos para aplicação prática voltada para a solução de problemas específicos e interesses locais. Do ponto de vista de abordagem do problema é dita como pesquisa quantitativa, de acordo com Zanella (2013), este tipo de pesquisa considera que tudo pode ser quantificável, o que significa traduzir em números opiniões e informações para classificá-las e analisá-las, utilizando recursos e técnicas estatísticas. Quanto aos objetivos, a pesquisa é descritiva, de acordo com Prodanov \& Freitas (2013) a pesquisa descritiva visa descrever as características de determinada população ou fenômeno ou o estabelecimento de relações entre variáveis. Envolve o uso de técnicas padronizadas de coleta de dados: questionário e observação sistemática. $\mathrm{E}$ quanto aos procedimentos técnicos a serem realizados, a pesquisa é considerada um estudo de caso, conforme Prodanov \& Freitas (2013) o estudo de caso envolve o estudo profundo e exaustivo de um ou poucos objetos de maneira que se permita o seu amplo e detalhado conhecimento.

\section{Indicadores utilizados}

Os indicadores utilizados no referido trabalho são semelhantes aos utilizados na metodologia de Castro (2016), onde o mesmo classificou os indicadores qualitativamente, em favorável, desfavoráveis e muito desfavoráveis. Ao mesmo tempo em que para possibilitar que os dados fossem de fácil entendimento optou-se por classificá-los, quantitativamente atribuindo valores 5, 3, e 1 respectivamente. Deste modo, com o término da pesquisa são somadas e feitas as avaliações. $\mathrm{O}$ presente trabalho procurou também evidenciar os indicadores em favorável (ao apresentar tendência à sustentabilidade socioeconômica e ambiental) e desfavorável (quando a atividade está em desacordo com a legislação ambiental vigente e/ou coloca em risco as condições sociais e de saúde humana) dando assim novos valores, 1 e 0 respectivamente, seguindo o modelo utilizado por Bento (2020) onde o mesmo se fez necessário para facilitar e compreender as variantes.

\section{Sujeitos da pesquisa}

Os sujeitos que foram investigados na pesquisa são pessoas que residem no Município de Uiraúna - PB, localizados em diferentes áreas urbanas, as informações que foram coletadas possibilitou a obtenção de dados mais confiáveis, devido ao fato do mesmo levar em consideração, uma maior amplitude de localidades e assim possibilitar dados mais coerentes à realidade estudada, proporcionando uma pesquisa com maior desempenho e colaborando para uma análise de qualidade de gestão dos resíduos no espaço urbano e posteriormente uma reflexão que procure contribuir na melhoria das disposições finais de resíduos sólidos naquela localidade.

Após levantamento do grupo a ser investigado, assumiram efetiva participação na pesquisa aqueles que assinaram o TCLE (Termo de Consentimento e Livre Esclarecimento), considerando os padrões éticos estabelecidos pela legislação em vigor. A referida pesquisa foi aprovada pelo Comitê de Ética em Pesquisa (CEP), CAAE 15390019.0.0000.5575.

\section{População, amostra e amostragem}

Os sujeitos que foram pesquisados são moradores de diferentes localidades do município. Considerando que o município possui 15.300 habitantes, foi utilizada a técnica de amostragem, onde esses atores sociais e institucionais foram selecionados com base no seu local de vivência e grau de importância por estarem diretamente relacionados com a problemática em questão. Foi 
pesquisado um número de sessenta e seis atores sociais residentes no Município de Uiraúna - PB, que representou $0,43 \%$ da população (Tabela 1 ).

Tabela 1. Número de atores sociais entrevistados.

\begin{tabular}{ll}
\hline \multicolumn{1}{c}{ Atores sociais e institucionais } & Número de entrevistados \\
\hline Representantes do poder público & 04 \\
\hline Representantes de escola & 04 \\
\hline Moradores dos bairros & 20 \\
\hline Profissionais da saúde & 05 \\
\hline Catadores & 15 \\
\hline Líderes sociais & 04 \\
\hline Comerciantes & 14 \\
\hline Total & 66 \\
\hline
\end{tabular}

\section{Coleta de dados}

A coleta de dados foi efetuada por meio da aplicação de questionários. De acordo com Prodanov \& Freitas (2013) estes expõem uma série ordenada de questões a serem respondidas pelos entrevistados da pesquisa. Sua utilização facilitou a obtenção de grande número de informações em um curto período de tempo no qual foi desenvolvida a pesquisa.

\section{Análise dos dados}

Logo após a avaliação dos dados ocorreu à classificação dos indicadores em favoráveis e desfavoráveis (tomando como referência a sustentabilidade no gerenciamento de resíduos sólidos na localidade), atribuindo valores distintos para cada um destes conforme o modelo usado por Castro (2016), e o desenvolvimento de sugestões objetivando melhoramento do gerenciamento de rejeitos daquela localidade.

\section{Resultados e Discussão}

A pesquisa contou com um total de sessenta e seis entrevistados, todos de bairros distintos do município de Uiraúna $\mathrm{PB}$, dos quais $63.6 \%$ que corresponde a 42 dos entrevistados foram do sexo masculino, já $36.4 \%$ que corresponde a 34 dos entrevistados foram do sexo feminino, resultado semelhante ao de Bento (2020), no qual o estudo realizado no município de Nazarezinho-PB demonstra um percentual maior com pessoas do sexo masculino do que com pessoas do sexo feminino. No entanto o mesmo também ressalta que estudos realizados no município de Cajazeiras-PB, o percentual dos entrevistados teve como maior grupo, pessoas do sexo feminino, destacando o horário comercial como possível fator de influência para o resultado. Desse modo, de acordo com os resultados, na localidade, pessoas do sexo masculino se apresentaram com maior expressividade.

Com relação à faixa etária, verificou-se que a maioria dos entrevistados tinham idade entre 30 a 40 anos, tendo um percentual de $36.4 \%$, que corresponde a 24 dos entrevistados, de 20 a 30 anos, teve um percentual de $34.8 \%$ representando 23 dos entrevistados, já os entrevistados com até 20 anos o percentual foi de $6.1 \%$ equivalente a 4 dos entrevistados, com 40 anos ou mais, foi constatado o percentual de $22.7 \%$ correspondendo a 15 dos entrevistados. Em pesquisa realizada por Barros et al. (2014), a média de idade predominante dos chefes de família foi de 40 a 60 anos, sendo contrários aos dados obtidos. Porém, dados registrados no município de Nazarezinho-PB por Bento (2020) constatou que a faixa etária dos chefes de família varia, sendo superior a 25 anos, assim demonstrando a semelhança entre os dados obtidos, onde mostra que 
os chefes de família com idade superior a 25 anos têm maior predominância, a concordância entre dados denotam uma realidade não só territorial, mas sim regional no Semiárido paraibano.

Quanto ao nível de escolaridade, verificou-se que a maior parcela dos entrevistados são pessoas que possuem o ensino médio completo com $34.8 \%$ correspondendo a 23 dos entrevistados, já os entrevistados com ensino superior completo somam $25.8 \%$, com ensino fundamental completo $15.2 \%$, ensino médio incompleto $10,6 \%$, com ensino superior incompleto $9,1 \%$, ensino fundamental incompleto $4.5 \%$. Nesse sentido, os resultados quando comparados aos de Vasquez et al. (2008) apresentam nível de escolaridade maior com relação aos entrevistados que possuem ensino médio completo e também ensino fundamental. Isso acontece também com os dados apresentados por Barros et al. (2014), no qual os dados obtidos mostram melhor nível de escolaridade. Já com Bento (2020) é possível observar a semelhança dos resultados em questão, pois o mesmo demonstra que ao longo dos anos houve o melhoramento no nível escolar dos comunitários.

\section{Conhecimento sobre os resíduos sólidos por parte da população}

Querino \& Pereira (2016) aponta que os seres humanos são dotados de inteligência e intelecto, no qual o homem tem consciência sobre esses materiais e através do mesmo subsidiar e prover sua sobrevivência extraindo o máximo do meio natural, impondo sua vontade para proporcionar bem estar e conforto.

Assim, tendo percepção e consciência desses resíduos, o ser humano interage, responde e percebe as diferentes alterações do meio, instigando a um entendimento mais amplo em relação à dinâmica entre homem-meio ambiente (Querino \& Pereira 2016). O público em sua maioria, quando questionados sobre o conhecimento do que são os resíduos sólidos, o resultado mostrouse positivo, correspondendo a $56.1 \%$. No entanto $43.9 \%$ demonstraram desconhecer o que são esses resíduos.

Oliveira et al. (2016) explica que ainda há muitas dúvidas por parte dos comunitários sobre o que são resíduos sólidos, ao mesmo tempo em que destaca a importância de políticas públicas e o desenvolvimento de ações voltadas para a educação ambiental na localidade. Assim considerando que a maioria dos entrevistados tem consciência no tocante ao conhecimento desses resíduos, é dito favorável, pois o percentual atinge um dado expressivo em relação ao que foi indagado.

\section{Resíduos sólidos produzidos}

A produção de resíduos pode variar de acordo com a população, tendo-se em vista que essa variação pode ser acarretada através de fatores como: períodos do ano, classe social, costumes do cotidiano, consumo de produtos semipreparados ou industrializados, localidades ou região onde mora (Oliveira et al. 2016). De acordo com os entrevistados, quando questionados sobre a produção de resíduos sólidos, $72.7 \%$ responderam que a maior produção de resíduos produzidos corresponde a resíduos inorgânicos, $27.3 \%$ afirmaram ser resíduos orgânicos. Conforme Rodrigues \& Menti (2016), isso é explicado devido à alta disponibilidade de produtos alimentícios integralizados ou semipreparados, dessa forma houve uma redução no descarte de resíduos orgânicos, em contra partida aumentou a incidência no descarte de resíduos inorgânicos.

Considerando que os resíduos inorgânicos são constituídos por: papel, vidro, papelão, plástico entre outros. Ciquetti (2004) aponta que os principais problemas ambientais estão relacionados a esses resíduos, destacando embalagem de produtos não degradáveis, produtos descartáveis ou tóxicos ao meio ambiente e/ou saúde das pessoas. Assim considera-se desfavorável, pois com relação à grande produção de resíduos inorgânicos torna-se preocupante caso não haja um destino final adequado a esses resíduos sólidos urbanos no município. 


\section{Execução da limpeza urbana}

O grande desafio das cidades em expansão é justamente proporcionar uma limpeza urbana de qualidade, que não consista em apenas retirar os resíduos das principais vias, logradouros e edificações, mas sim possibilitar uma disposição viável e adequada para esses resíduos (Giaccom-Ribeiro \& Mendes 2018).

Com base nos resultados obtidos, $75.8 \%$ dos entrevistados declararam que a execução da limpeza urbana fica a cargo da prefeitura municipal, já $4.5 \%$ afirmaram que a limpeza urbana era realizada por outros, e $19.7 \%$ dos entrevistados responderam que prefeitura em convênios com outros órgãos. De acordo com os dados analisados, Giaccom-Ribeiro \& Mendes (2018) relata que as prefeituras não dispõem de aparato técnico e financeiro para arcar com a problemática ligada à gestão de resíduos. Desse modo torna-se desfavorável, pois mesmo que a instituição seja responsabilizada por tornar viável o descarte final desses resíduos, a mesma não possui recursos suficientes para proporcionar o gerenciamento desses resíduos de forma eficaz, tornando a problemática ainda mais preocupante.

\section{Coleta de lixo dentro do município}

Lixo é definido como tudo que é descartável, que não tem mais serventia, inútil ou indesejável, proveniente da ação humana que varia do sólido ou semissólido (Moreira et al. 2017). Para Lima \& Barros (2019), esses resíduos em via pública podem representar um alto risco à população, tendo-se em vista que seu acúmulo favoreça o aparecimento de agentes transmissores de doenças. Assim a coleta de resíduos sólidos torna-se um fator essencial na prevenção de possíveis focos de doenças no município.

Com os dados analisados, $66.7 \%$ dos participantes declararam que a coleta do lixo abrange todo município, já 33.3\% responderam que não. Considerando o resultado obtido, é dito favorável, pois a coleta desses resíduos acontece por todo município.

\section{Cobrança pelos serviços de limpeza}

Leite (2006) aponta que a limpeza urbana é um dos maiores investimentos realizado por municípios brasileiros, onde a coleta, transporte e destinação final desses resíduos sólidos estão dentro dos serviços fornecidos pelos municípios. No qual a cobrança por serviços de limpeza por parte do município é inconstitucional, tendo a mesma sido rejeitada pelo supremo tribunal federal.

De acordo com os dados coletados $78.8 \%$ dos participantes destacam que os serviços disponibilizados pelo município não carecem de pagamentos por parte da população, pois o município arca com os custos relacionados à coleta e ao descarte final desses resíduos. Ainda neste aspecto, $15.2 \%$ destacam que sim, $3.0 \%$ afirmam que é cobrada uma taxa, outros $3.0 \%$ responderam que é cobrado junto ao IPTU. Dentro desse contexto, de acordo com os dados analisados, é dito favorável, pois o serviço de limpeza está acessível sem cobrança de taxa a todos os habitantes do município.

\section{Conhecimento da população acerca da coleta seletiva}

A coleta seletiva torna-se um fator importante no que diz respeito à preservação do meio ambiente e sustentabilidade. A mesma consiste na separação desses resíduos, separando os orgânicos dos inorgânicos, permitindo assim um descarte viável e adequado. Os materiais que são coletados e reciclados em sua maioria são papéis, vidro e metais (Moreira et al. 2017).

Quando indagados a respeito do que é coleta seletiva, $74.2 \%$ dos entrevistados apontaram que tinha conhecimento sobre a coleta seletiva, enquanto $25.8 \%$ responderam que não. Dado semelhante aos estudos de Bento (2020) em que, no município de Nazarezinho-PB o percentual da população em relação ao conhecimento do que seria coleta seletiva atingiu um percentual de $80 \%$. Tendo-se em vista essa realidade, conforme Moreira et al. (2017), para que se tenha êxito no 
que diz respeito à coleta seletiva, é necessário à conscientização da população em relação aos resíduos gerados, podendo os mesmos separá-los antes da coleta.

Deste modo a conscientização da população torna-se por fim o primeiro passo a ser dado, tendo-se em vista que a população tem papel fundamental no processo. Deste modo, torna-se favorável, pois tendo ressaltado que a população tem um papel fundamental no processo de conscientização, a mesma contribui para um ambiente mais sustentável aumentando sua qualidade de vida.

\section{Período em que a coleta é realizada}

Em concordância com Lima \& Barros (2019) a coleta no município é feita diretamente nos bairros dos residentes pelos agentes de limpeza no qual esses resíduos são transportados por caminhões tendo sua disposição final no vazadouro.

De acordo com os dados obtidos, quando questionados sobre o período em que o serviço de coleta passa para fazer o recolhimento, $74.2 \%$ dos entrevistados afirmaram que a coleta é realizada semanalmente na cidade, diária e alternada ambas com $9.1 \%$ e eventualmente $7.6 \%$ respectivamente.

Assim é classificado como favorável, pois a coleta dos resíduos sólidos urbanos no município é feita de forma regular, sendo realizada semanalmente e abrangendo todos os bairros do município em questão.

\section{Grau de satisfação com a coleta de resíduos}

O processo de coleta ocorre por etapas, onde acontece desde a saída do veículo coletor do estacionamento de sua garagem, abrangendo o trajeto em que o veículo gasta recolhendo os resíduos dos locais em que foram acondicionados, aos locais de disposição, até retornar ao ponto de partida (Cunha \& Caixeta Filho 2002).

De acordo com os dados obtidos, $36.4 \%$ dos entrevistados consideram a qualidade da coleta boa, a segunda resposta mais obtida, foi que a qualidade era regular, com $34.8 \%$ da população entrevistada. Para $19.7 \%$ a qualidade da coleta é ótima, já $9.1 \%$ a consideram ruim.

Dessa forma considera-se favorável, pois analisando os resultados, a coleta abrange todo município, mesmo em que alguns casos não haja a disposição adequada ou a coleta de forma efetiva.

\section{Conhecimento da população sobre a disposição final dos resíduos no município}

De acordo com Vieira \& Garcia (2012), no Brasil verificou-se que em 2006 foram gerados por volta de 51.1 milhões de toneladas de rejeitos, tendo-se em vista que $18 \%$ do total foram metais, papeis, plásticos e vidro que foram reciclados.

A problemática em questão torna-se um grande desafio para os municípios brasileiros que ainda em sua maioria lançam seus resíduos em vazadouros a céu aberto, onde dados obtidos pelo instituto brasileiro de geografia e estatística mostram que 50.8\% dos resíduos produzidos no país têm sua disposição destinada a lixões no qual pode ser constatado que seu agravo maior é na região norte do país em que os municípios lançam cerca de 59\% dos seus rejeitos em vazadouros a céu aberto (Costa et al. 2016).

No município de Uiraúna, os entrevistados quando perguntados sobre para onde vão os resíduos produzidos, $72.7 \%$ responderam que esses resíduos têm sua disposição destinada a lixões, $13.6 \%$ dos entrevistados afirmaram que esses resíduos eram destinados a aterros sanitários, 3.0\% disseram que eram incinerados, $10.6 \%$ desconhece a destinação final desses resíduos. Em concordância com Costa et al. (2016), a disposição inadequada desses resíduos pode comprometer o equilíbrio do ecossistema, havendo poluição da água, do ar e também do solo, possibilitando a proliferação de agentes causadores de doenças.

Desse modo com os dados coletados é dito desfavorável, pois no município em questão, não existe aterro sanitário e seus resíduos são encaminhados a lixões. 


\section{Como são armazenados os resíduos produzidos nas residências}

Considerando que no ciclo do gerenciamento de resíduos, após a produção e a utilização desses resíduos, ocorre o armazenamento, o mesmo pode ser classificado em três etapas: adequado, inadequado e inexistência de acondicionamento. Desse modo, adequado seria a utilização de sacos plásticos, baldes ou latas com tampas, já a forma inadequada de se armazenar esses resíduos estão: baldes sem tampa, caixotes de madeira e caixas de papelão (Bento 2020).

Assim, de acordo com os entrevistados quando questionados sobre a forma com que os mesmos armazenam os resíduos produzidos em suas residências, $62.2 \%$ responderam que armazenam o lixo em uma lixeira plástica com tampa, já 36.4\% dos entrevistados afirmaram que acondiciona os resíduos em um saco plástico. Nesse aspecto é dito, favorável, pois é considerado que os residentes armazenam os rejeitos de forma adequada.

\section{Separação dos tipos de resíduos}

A separação de resíduos é de fato uma atividade pouco utilizada pela população que acondiciona seus rejeitos sem qualquer tipo de segregação, ou seja, os resíduos são armazenados de maneira em que papéis, plásticos, metais e resíduos orgânicos compartilham o mesmo recipiente em que serão recolhidos pelos profissionais de limpeza pública.

Dentro dessa realidade os catadores que atuam na coleta de porta a porta estão sujeitos a diversos tipos de risco. Quando não há o acondicionamento de forma adequada do lixo, os catadores à medida que realizam a coleta podem sofrer com cortes por metais, vidros, agulhas entre outros materiais justamente pelo fato dos cidadãos não fazerem a separação de forma adequada (Klein et al. 2018).

Com base nos dados observados, quando questionados com relação se os mesmos fazem a separação dos resíduos domésticos, $54.5 \%$ dos entrevistados responderam que não fazem a separação, $45.5 \%$ afirmaram que sim, que segregam os resíduos produzidos. Sendo assim, este aspecto é considerado desfavorável, tendo em vista que a maioria não realiza a separação do lixo podendo prejudicar tanto profissionais de limpeza como também o meio ambiente no qual estão inseridos.

\section{Reutilização dos resíduos por parte dos entrevistados}

A reutilização de resíduos tornou-se de grande relevância no período pós-guerra, no qual habitantes dos países que foram afetados pela guerra começaram a reutilizar materiais transformando-os, a fim de subsidiar a sua sobrevivência. No Brasil, a ideia de reutilização ou reciclagem dos resíduos tornou-se bastante conhecida devido a ECO-92. Depois desse evento o mundo tomou conhecimento com questões relacionadas à conservação e preservação do meio ambiente (Souza \& Mello 2015).

Com essa perspectiva, a reciclagem auxilia na diminuição dos resíduos coletados, facilitando o trabalho dos profissionais de coleta, à medida que contribui maximizando a renda familiar dos catadores que trabalham na reciclagem desses resíduos.

Nesse aspecto $74.2 \%$ responderam que não reutilizam de nenhuma forma os resíduos consumidos, enquanto que $25.8 \%$ afirmaram que reutilizam, porém em sua maioria plástica e vidro. Dentro dessa realidade é possível constatar que a maioria da população não reutiliza os resíduos, destacando esse aspecto como desfavorável.

\section{Separação de resíduos para reciclagem}

Para Silva \& Nolêto (2004), torna-se importante a divulgação de conhecimentos sobre a forma adequada de separação de resíduos, de maneira que seja ampliada, não só para as residências dos moradores, mas também para restaurantes, bares, áreas de lazer e etc., fazendo com que seja divulgada diariamente para que a população esteja sempre em alerta. Nesse caso, a inexistência de meios que possam viabilizar a comunicação entre população e setor público 
sobre formas adequadas de manejo desses resíduos pode consequentemente por parte da população haver o acondicionamento de forma errada.

Nesse quesito as afirmações negativas tiveram em sua maioria a totalidade de $57.6 \%$, enquanto que os que separam o lixo para reciclagem correspondem a $42.4 \%$, assim foi possível evidenciar que a maior parcela da população não separa os resíduos produzidos, enquanto que o percentual que faz a segregação desses resíduos realiza a separação entre os rejeitos orgânicos de inorgânicos. Feita análise dos dados coletados este quesito é considerado desfavorável.

\section{A utilização de produtos mais sustentáveis}

Em um contexto social em que o consumo desenfreado da população permite a geração de resíduos de forma desordenada, torna-se necessário a criação de estratégias para mitigar os efeitos proporcionados pela alta produção e descarte inadequado desses resíduos.

Isso é agravado ainda mais, devido à escassez de conhecimento por parte da população com relação à educação ambiental atrelado a uma sociedade desorganizada em questões sociais e econômicas (Pordeus et al. 2019).

Nesse aspecto é necessária uma visão direcionada ao consumo moderado dos recursos ambientais preocupando-se com o bem atual e o consumo futuro, dessa maneira deve existir o bem estar social/econômico, participação democrática do cidadão e sustentabilidade ambiental (Vicente et al. 2016).

Tendo-se em vista essa realidade, a utilização de produtos que agridam menos o meio ambiente pode promover equidade em consumo/geração de resíduos, adotando também formas de reutilização, pois de acordo com Vicente et al. (2016), adotando técnicas como a reciclagem, é dado o primeiro passo para o combate ao consumismo desenfreado desestabilizando a cadeia de consumo e descarte inadequado de resíduos.

Para essa questão, foi analisado que $57.6 \%$ dos entrevistados utilizam produtos sem se preocupar que os mesmos possam agredir o meio ambiente, $42.4 \%$ procuram usar produtos menos agressivos ao meio ambiente, dessa forma foram possíveis constatar que a população em sua maioria utiliza produtos sem se preocupar se os mesmos podem ou não prejudicar o meio ambiente, assim caracterizando esse quesito como desfavorável.

\section{Grau de satisfação da coleta seletiva}

A coleta seletiva é um serviço sistemático, em que funciona de forma a segregar o material coletado, ao mesmo tempo em que facilita e diminui os rejeitos levados para os locais de descarte, fazendo com que o material seja valorizado, promovendo sua reutilização dentro do meio de produção (Leite 2006).

Assim as associações e cooperativas de catadores tornam-se um meio importante para auxiliar na comunicação entre os setores do poder público, privado e população de modo geral, enfatizando uma abordagem integrada a respeito da coleta seletiva, de modo que os setores proporcionem condições para que esses profissionais atuem de forma efetiva (Klein et al. 2018).

Klein et al. (2018) também ressaltam a situação dessas associações e cooperativas, no qual suas atividades em alguns municípios brasileiros atuam de maneira informal, mesmo sendo regida pela PNRS, maior parcela ainda exercem suas funções de forma irregular ou individual.

No Município de Uiraúna - PB a coleta seletiva é realizada semanalmente onde a mesma acompanha o cronograma da coleta de resíduos nos respectivos dias, segundas, quartas e sextas, sendo realizada pela associação de catadores do Município. Para 47\% dos entrevistados, a coleta seletiva é realizada de forma efetiva, classificada como boa, já para $27.3 \%$ classificaram como regular, $22.7 \%$ responderam que a coleta seletiva é ótima, para os outros $3.0 \%$ classificaram como ruim. Deste modo é dito favorável, aonde a coleta seletiva vem sendo realizada de forma efetiva atendendo toda a demanda do município em questão. 


\section{Disposição final de resíduos hospitalares do município}

Resíduos hospitalares ou resíduos de serviços de saúde são conceituados como rejeitos provenientes das atividades realizadas em unidades de saúde como, clínicas odontológicas, hospitais, clínicas veterinárias, ambulatórios, postos de saúde e etc. (Cafure \& PatriarchaGraciolli 2015).

Esses resíduos, pelo fato de provocar contaminações, podem se tornar um problema de saúde pública, podendo comprometer também a qualidade de vida da população que estão em contato direto ou indireto com esses resíduos hospitalares (Cafure \& Patriarcha-Graciolli 2015).

De acordo com a secretaria de saúde do município, os resíduos hospitalares possuem um descarte realizado pela empresa no qual tem convênio, e garante que esses resíduos possuem uma disposição adequada para os mesmos. Assim para os entrevistados quando questionados sobre a destinação desses resíduos, $77.3 \%$ responderam que desconhece o descarte desses resíduos, para $22.7 \%$ afirmaram que tem conhecimento para onde vão esses resíduos.

Apesar da maioria dos entrevistados desconhecerem para onde vão os resíduos hospitalares, o município acondiciona e possibilita um destino viável e adequado para esses resíduos, desse modo o mesmo é dito como favorável.

\section{Conhecimento sobre os perigos dos resíduos hospitalares}

Os resíduos sólidos, de modo geral, sem o cuidado necessário ocasionam grande prejuízo ao meio ambiente e consequentemente a perda da qualidade de vida da população (Cabral et al. 2015). Porém quando se trata de resíduos hospitalares o risco em relação torna-se potencializado, pois o mesmo possui um alto risco biológico, ou seja, são capazes de disseminar doenças.

Com tudo vale ressaltar que normas, diretrizes e leis são estabelecidas para o manejo adequado desses resíduos, no entanto ainda existe o acondicionamento inadequado desses rejeitos (Cafure \& Patriarcha-Graciolli 2015).

Assim de acordo com Camargo et al. (2009), é de grande importância o controle responsável desses resíduos possibilitando técnicas e soluções de maneira que possa ter uma coleta viável e segura, local de armazenamento, tratamento de disposição final adequada.

Já com relação a baterias e pilhas, Bento (2020), explica que esses resíduos, quando não acondicionados de maneira adequada, podem prejudicar consideravelmente o meio ambiente, podendo resultar na liberação de seus componentes tóxicos no meio natural, havendo assim a contaminação dos recursos naturais, diminuindo a qualidade de vida do ser humano.

Para este indicador $86.4 \%$ dos entrevistados demonstrou ter conhecimento sobre os perigos desses rejeitos a saúde, tanto humana como ambiental, os que desconhecem representam um percentual de $13.6 \%$ dos entrevistados. Este indicador é considerado favorável, pois a população tem conhecimento sobre os riscos a saúde humana e ambiental proporcionado por esses resíduos.

\section{Aceitação popular com relação às campanhas de conscientização ambiental}

O meio ambiente sempre foi uma temática que gerou várias discussões em diversos setores, refletindo assim em aspectos como economia, política e também no modo de vida da sociedade contemporânea. Dentro dessa realidade, é bem verdade que há um aumento no número de associações, institutos, organizações governamentais e não governamentais que procuram implantar políticas de conscientização, ao mesmo tempo em que também visam educar sobre atividades ambientalmente adequadas (Cavalcanti 2013).

Assim através da divulgação de conhecimentos, esses órgãos corroboram para a divulgação de campanhas e palestras, utilizando tecnologias a fim de incentivar a população sobre a importância da temática (Carvalho \& Estender 2017).

Quando indagados sobre sua opinião com relação ao desenvolvimento de campanhas de conscientização ambiental, os entrevistados se mostraram em sua maioria favorável, constatando $89.4 \%$ dos casos, contra $10.6 \%$, considerando então favorável para este indicador, vista que a 
população se mostrou receptiva as possíveis orientações que possam ser adotadas através de campanhas de conscientização.

\section{Forma com que a população gostaria de receber esse tipo de orientação}

Seguindo o modelo de Bento (2020), nesse indicador e para os próximos a seguir, sua avaliação foi diferente das demais realizadas, nesse aspecto foi aceito mais de uma alternativa escolhida pelo entrevistado, em que constavam as orientações em específico no qual o mesmo gostaria de receber, desse modo o entrevistado poderia ter um leque de escolhas no questionário e assim poderia escolher as alternativas mais viáveis para receber esse tipo de orientação. Para verificação das porcentagens do indicador supracitado e os próximos a seguir, foi realizado a soma das afirmações dos entrevistados, onde a média de alternativas escolhidas pelo público ficou entre 2 e 3 alternativas, desse modo através do cálculo básico de regra de três simples foi possível tornar mais simples seu entendimento.

Nesse quesito $62.12 \%$ concordaram que a forma mais viável para receber esse tipo de orientação seria por visitas em suas residências, enquanto que reuniões comunitárias e informações por rádio tiveram ambas um percentual semelhante com $16.67 \%$ das afirmações, já $15.15 \%$ preferem que essas orientações sejam vinculadas através de panfletos ou cartazes, $4.55 \%$ dos entrevistados preferem a divulgação por jornais. Considera-se favorável em questão, vista que a população está de acordo e aceita as formas de divulgação e orientação sobre as questões ambientais.

Dentro dessa realidade as tecnologias utilizadas para a disseminação e propagação de material relacionado a questões ambientais possibilitam o desenvolvimento da sociedade, fazendo com que busquem meios mais sustentáveis evitando o desperdício, promovendo a divulgação sobre ações como a reciclagem, a coleta seletiva, de maneira que a população possa contribuir de forma efetiva na conservação do meio ambiente (Carvalho \& Estender 2017).

\section{Tipos de materiais consumidos nas residências}

Os plásticos são materiais oriundos do petróleo, que é uma matéria-prima considerada barata, com vida útil durável e bastante versátil, facilitando o desenvolvimento de produtos para a sociedade, no entanto esses materiais podem causar sérios danos ao meio ambiente e a saúde humana devido aos aditivos químicos utilizados na fabricação do mesmo (Oliveira 2012).

Quando questionado sobre o tipo de material produzido em suas residências, o material orgânico foi o que apresentou maior quantidade nas residências dos participantes, somando $53.03 \%$, em segundo vem o plástico com $50 \%$, outros $48.48 \%$ afirmaram ser o papel. Assim de acordo com os dados, este indicador torna-se desfavorável, pois apesar dos resíduos orgânicos serem produzidos em sua maioria nas residências dos entrevistados, é constatado que os resíduos inorgânicos são consumidos sem que haja reciclagem ou reutilização dos mesmos.

\section{Tipos de lixos produzidos dentro do município}

Segundo Rodrigues \& Menti (2016), diante de um modo de vida consumista, agregado a modernização das tecnologias, permitiu que os produtos ficassem obsoletos potencializando o consumo desenfreado, consequentemente aumentando o descarte desses resíduos pela própria população.

Quando questionados sobre os resíduos produzidos dentro do município, 65.15\% declararam que o tipo mais produzido de lixo dentro do município seria o público, resíduo proveniente de atividades de varrição de praças e de outras formas de limpeza pública, em segundo com $31.81 \%$ lixo domiciliar, $15.15 \%$ responderam resíduos comerciais, lixo agrícola e entulho tiveram percentuais semelhantes, ambas com $9.09 \%$, outros $4.54 \%$ declararam lixo industrial. $\mathrm{O}$ referido indicador torna-se favorável, pois o lixo proveniente da população em maior quantidade dentro do município são resíduos que podem ser recicláveis, diminuindo assim os resíduos coletados caso haja coleta seletiva dentro do município. 


\section{Principais problemas ocasionados pelo descarte inadequado de resíduos segundo a população}

Não é de agora que a população vem sentindo os impactos que esses resíduos vêm provocando à saúde humana, desde a antiguidade o homem vem sofrendo com os efeitos negativos desses rejeitos, isso devido à forma inadequada de manejo, onde pode ser evidenciado no século XVIII e XIX em que houve o rápido crescimento no setor industrial e também de urbanização (Siqueira \& Moraes 2009).

Soares et al. (2017) aponta que a falta de recursos para investir na gestão de resíduos seria o principal problema para o manejo inadequado do mesmo, isso também atrelado à falta de esforço e interesse por parte do setor público para tomar medidas mais efetivas, além da falta de cobrança da população. Nesse contexto, o lixo quando acumulado permite a geração de maus odores, além de ser o precursor de vários tipos de doenças. Quando não tratado de forma adequada, o mesmo torna-se um risco em potencial à qualidade de vida da sociedade e ao meio ambiente.

Tendo-se em vista esse indicador, $74.24 \%$ das afirmações foram direcionadas à preocupação com a saúde da população, no entanto não foi evidenciado que algum popular tenha sido contaminado por doenças decorrentes da presença do lixão, $24.24 \%$ responderam que a presença desses resíduos comprometia principalmente a qualidade do ambiente e seus recursos naturais, $12.12 \%$ questionaram a geração de mau odor que esses rejeitos provocavam. Assim, o indicador é tido como favorável, pois os populares se preocupam com relação à sua saúde e têm conhecimentos dos riscos que esses lugares representam à sua saúde.

\section{Principais responsáveis pelos danos causados ao meio ambiente}

Com o crescimento exponencial da população associado à evolução industrial no século XVIII foi se intensificando os impactos ambientais. Em decorrência disso houve acúmulo de lixo nas principais avenidas e ruas, fazendo com que seu acúmulo tornasse possível o surgimento de doenças e consequentemente levando a mortes milhares de pessoas (Giaccom-Ribeiro \& Mendes 2018).

Nos tempos atuais o meio ambiente cada vez mais vem sendo afetado pela atividade humana. De acordo com Soares et al. (2017), a causa desses impactos é justamente em decorrência do modo de vida que o homem exerce, visando alto poder econômico e bens de consumo.

Segundo os entrevistados o maior responsável, com $66.7 \%$ das indicações é a própria população, sendo que muitos dos entrevistados criticam o hábito das pessoas jogarem seus resíduos em locais inadequados, principalmente em terrenos baldios tornando esses locais focos de possíveis doenças. Com $18.2 \%$ os mesmos responsabilizam a prefeitura, pois sendo órgão público, o setor deveria estar mais comprometido em disponibilizar um serviço de qualidade para a população. Como maiores responsáveis pela degradação do meio ambiente, tanto o setor agrícola como o comercial tiveram $6.1 \%$ das indicações, $1.5 \%$ apontaram o setor industrial como maior responsável. De acordo com os dados analisados, este indicador é dito como favorável, pois a população é ciente de seu hábito inadequado ao mesmo tempo em que reconhece os impactos ambientais ocasionados devido ao descarte inadequado desses resíduos, além de reconhecerem que os setores poderiam fornecer um serviço melhor para a população.

\section{Considerações sobre a qualidade do atual local de disposição de resíduos do município}

Conforme Sousa et al. (2019), os vazadouros a céu aberto, popularmente conhecido como lixão, correspondem a um local em que são descartados resíduos de maneira indiscriminada, sem planejamento e nenhum controle com relação aos impactos ambientais. O mesmo também ressalta que a disposição de resíduos nesses locais além de ser inadequada é ilegal, onde enfatiza que o local adequado para que se haja a disposição de forma correta seriam os aterros sanitários, que são locais controlados e ambientalmente adequados. 
Nesse sentido podemos concluir segundo Gomes et al. (2015) que os aterros sanitários são os locais mais indicados para a disposição desses rejeitos, onde possuem qualidade com relação a técnicas e métodos utilizados para o controle desses resíduos fazendo com que haja a redução dos impactos ambientais.

Questionados sobre a qualidade do local em que é feita a disposição dos resíduos do município, 54.5\% responderam que tem consciência que o local de descarte não é o mais adequado, pois o local não apresenta segurança ao mesmo tempo em que pode ocasionar risco à saúde humana e também causar prejuízo ambiental. Os dados obtidos indicam também que $45.5 \%$ dos atores sociais entrevistados desconhecem o perigo que esses locais representam à qualidade de vida e também ambiental. Desse modo este indicador se apresenta como desfavorável, pois a maior parte da população sabe que o local precisa ser melhorado, no entanto o mesmo se encontra ainda com sua utilização inadequada.

\section{Implantação de um sistema de aterros sanitários segundo os entrevistados}

De acordo com Portela \& Ribeiro (2014) aterro sanitário é o local onde são direcionados adequadamente os resíduos provenientes das atividades humanas, de modo que a disposição desses resíduos é controlada e planejada, fazendo com que ocorra o mínimo de impacto ao meio ambiente.

Contudo o aterro sanitário busca métodos e técnicas da engenharia para tornar possível sua construção em uma área com espaço pequeno e reduzir ao máximo esses resíduos, tendo qualidade e ser bem favorável no que diz respeito ao custo/benefício (Conde et al.2014).

Sousa et al. (2019) apontam que apesar de ter formas mais sustentáveis de disposição desses resíduos, a maioria dos municípios brasileiros ainda não possuem locais controlados para o descarte dos resíduos. Os municípios pequenos são aqueles que ainda sofrem com esse tipo de situação, por não possuírem equipes técnicas capazes de tornar viáveis e criar medidas mais eficazes.

Segundo a opinião dos entrevistados, a respeito da implantação de um sistema de aterro sanitário $40.9 \%$ dos participantes responderam que seria ótima a implantação do mesmo, vista que os resíduos direcionados ao aterro sanitário seriam tratados de forma adequada e responsável, $34.8 \%$ responderam que seria boa a introdução desse sistema. Considerando que a maior parte de população vê como uma melhoria a instalação do aterro sanitário no município, este indicador é classificado como favorável.

\section{Opinião sobre o descarte de resíduos em aterros sanitários}

O aterro sanitário é considerado o local mais adequado para disposição de resíduos sólidos, onde o mesmo consiste em técnicas sanitárias para melhor manejo dos resíduos produzidos, bem como o tratamento de gases e também do chorume proveniente do acúmulo de lixo (Portela \& Ribeiro 2014).

Conforme Bernardo \& Lima (2017) o papel que a coleta seletiva tem dentro da sustentabilidade é de grande valia, pois a mesma auxilia nos processos de preservação do meio ambiente, vista que, a utilização da coleta seletiva tem impacto significativo na diminuição de resíduos sólidos, além de fazer com que aquele resíduo retorne para o meio de consumo.

Assim o aterro sanitário agregado com o sistema de coleta seletiva possibilita a vida útil do aterro, ao mesmo tempo em que permite a introdução da educação ambiental, reforçando a importância de uma consciência ecológica, permitindo uma maior participação da população (Portela \& Ribeiro 2014).

Considerando a opinião dos participantes, quando perguntados sobre o tipo de lixo que deveria ser descartado nos aterros sanitários, em sua maioria, 34.8\% responderam que o lixo hospitalar precisa de um destino diferente dos demais, pois o processo de manejo requer técnicas mais especializadas, em segundo com $28.8 \%$ afirmaram que sim, que o aterro sanitário deveria receber qualquer tipo de lixo produzido, $24.2 \%$ considera que, para que haja o descarte desses resíduos devem levar em consideração o tipo de resíduo a ser descartado, outros $12.1 \%$ 
responderam que pilhas e baterias deveriam ser devolvidas paras as indústrias fabricantes para um melhor gerenciamento. Desse modo o indicador avaliado é classificado com favorável, pois a maior parcela da população tem conhecimento que alguns materiais necessitam de um local de descarte mais apropriado.

\section{Local adequado para o descarte de resíduos sólidos segundo a população}

No Brasil a forma de manejo e disposição de resíduos sólidos por parte da maioria dos municípios brasileiros é considerada inadequada, pois sua disposição final é acondicionada a vazadouros a céu aberto, contribuindo para o aumento dos impactos ambientais colocando assim em risco a qualidade de vida da população. $O$ mesmo também ressalta que a falta de locais adequados para seu descarte é um fator que torna ainda mais difícil a resolução dessa problemática (Costa et al. 2016).

É importante que a população reivindique melhorias no tocante a gestão desses resíduos, pois segundo Sousa et al. (2019) a sociedade tem papel importante na tomada de decisões no que diz respeito às questões ambientais, vista que nos tempos atuais a democratização das políticas públicas voltadas para o meio ambiente estão mais situadas.

Segundo a opinião dos entrevistados, quando perguntados se os mesmos gostariam que o município tivesse um local adequado para a disposição dos resíduos, os participantes se mostraram em sua maioria favorável ao questionamento, onde $68.2 \%$ afirmaram que sim, que o município deveria ter um local adequado para o acondicionamento desses rejeitos, enquanto que $31.8 \%$ responderam que não. Esse indicador é classificado como favorável, pois a população anseia por um local adequado para o tratamento dos resíduos sólidos.

\section{Existências de moradias perto de vazadouros a céu aberto}

Bento (2020) aponta que o lixo depositado próximo às residências da população contribui para possíveis focos de agentes transmissores de doenças além de permitir a contaminação do ambiente. Sousa et al. (2019) afirma que 50.8\% dos resíduos produzidos no Brasil têm como destino final terrenos baldios, lixões, fundos de vales e etc.

Com relação à existência de moradias próximas a vazadouros a céu aberto, foi evidenciado que $27.3 \%$ dos participantes declararam morar perto desse tipo de local, apontando também que outros espaços próximos seriam similares, ao espaço supracitado, $72.7 \%$ responderam que não residiam próximos a esses locais. Considerando que há a presença de moradias perto desses logradouros a céu aberto ou similares, este indicador torna-se desfavorável, pois há uma grande possibilidade da população se contaminar com esses resíduos próximos.

\section{Conhecimento por parte da população sobre relatos de contaminações devido ao contato com os resíduos}

De acordo com Costa et al. (2015) o lixiviado é considerado principal fator para a contaminação do solo, das águas superficiais e subterrâneas, tendo um alto poder de impacto ambiental, o mesmo vem sendo analisado e estudado há mais de 30 anos. Costa et al. (2015) explica que o lixiviado é uma substância resultante das misturas de resíduos orgânicos e inorgânicos, tornando-se uma substancia complexa e com alta concentração de matéria orgânica recalcitrante possuindo também alto teor tóxico. Além disso, Bento (2020) afirma que existindo logradouros a céu aberto, outros fatores podem contribuir para possíveis focos de doenças, como a existência de animais, insetos, o surgimento de mau odor.

Quando indagados sobre o conhecimento de casos de contaminação acometidos devido ao contato com resíduos, $69.7 \%$ dos entrevistados afirmaram ter conhecimentos de casos ocorridos com pessoas residentes próximas a esses locais, questionando que as doenças eram de algum tipo de bactéria adquirida nesses locais, já outros $30.3 \%$ desconhecem qualquer tipo de caso relacionado. Com isso este indicador é classificado como desfavorável. 
Relatos de moradores sobre a presença de logradouros a céu aberto próximo as suas residências

Os lixões municipais conforme Correia et al. (2018) são espaços que representam uma problemática que atinge todas as esferas, tanto econômica, como social, espacial, ambiental e geopolítica. Desse modo esses espaços onde são acondicionados os resíduos são considerados ilegais, onde o mesmo ressalta que de acordo com a lei 9.605/98 a implantação de logradouros a céu aberto é crime ambiental, devido ao prejuízo que isso acarreta contra a fauna e a flora, além da poluição e contaminação do solo e das águas.

Segundo os entrevistados, $74.2 \%$ já ouviram vizinhos, colegas e até familiares ressaltarem sua insatisfação relacionada a esses locais de descarte, pois o motivo seria a existência de mau odor e possíveis agentes transmissores de doenças afetando a qualidade de vida dos populares, outros $25.8 \%$ declararam que não. Assim o indicador avaliado é considerado desfavorável.

\section{Conhecimento de áreas degradadas que foram recuperados no município}

Para Ferreira et al. (2019) área degradada é aquele local que de alguma forma sofreu com impactos desencadeados por algum tipo de distúrbio sendo natural ou sendo ocasionado por atividades exercidas por seres humanos, havendo assim o prejuízo ambiental e também a perda da regeneração da fauna e flora daquela localidade.

De acordo com Bento (2020) para que haja a recuperação de áreas degradadas, deve haver principalmente retirada e substituição de toda área prejudicada, ao mesmo tempo em que se utilizem técnicas especializadas a fim de facilitar a adaptação da fauna e flora naquele novo ambiente.

Questionados sobre o conhecimento de áreas degradadas que foram recuperadas, a maioria dos entrevistados, 66.7\% afirmaram não conhecer áreas que de alguma forma foram recuperadas pela administração pública ou pelo setor privado. Ainda neste aspecto, 33.3\% declararam que sim, ou seja, houve recuperação de algumas localidades, porém os mesmos responderam que sua recuperação foi feita com o propósito de amplio da área urbana do município. Dessa maneira é classificado como desfavorável, visto que nenhuma política pública foi implantada para a recuperação de áreas degradadas.

\section{Importância do distanciamento das residências desse tipo de local}

Segundo Klein et al. (2018) com a disposição inadequada desses resíduos os impactos ambientais provocados, podem por em risco a saúde pública e a qualidade de vida dos moradores que podem residir próximo a esses locais, provocando também desgaste ambiental e contaminação do solo e da água.

Perguntados sobre a importância do distanciamento de suas residências dos logradouros a céu aberto como forma de mitigar os efeitos provocados à qualidade de vida dos moradores, foi constatado que $100 \%$ dos participantes concordam com o distanciamento desses locais de suas residências, desse modo é classificado como favorável, pois a população sabe da importância do distanciamento que permite melhor a preservação de sua saúde.

\section{Descarte de resíduos no meio ambiente}

Quando ocorre a eliminação desses resíduos de modo inadequado no meio ambiente, o mesmo sofre com os efeitos resultantes desse descarte, havendo a contaminação do meio natural e perca de qualidade de vida da população (Ferreira et al.2019).

Oliveira et al. (2016) afirmam que os logradouros a céu aberto prejudicam a dinâmica do meio ambiente, devido às possíveis contaminações do solo, da água, do ar, além da presença de animais como ratos e urubus que são vetores de agentes transmissíveis de doenças.

Nesse quesito quando questionados sobre quais recursos poderiam ser prejudicados devido ao descarte desses resíduos de forma inadequada no meio ambiente, $60.61 \%$ responderam que a saúde da população seria a mais afetada, $56.06 \%$ ressaltaram que poderia comprometer a fauna e flora daquele local afetado, $37.88 \%$ afirmaram que a água seria afetada, $15.15 \%$ que haveria a 
perca da qualidade do ar, outros $24.24 \%$ declararam o solo. Este indicador é classificado como favorável, pois a população reconhece que esses resíduos afetam na qualidade de todos os recursos disponíveis para a população.

\section{Considerações finais}

O estudo abordado é uma problemática que vem sendo discutida há muito tempo no meio acadêmico, onde é possível constatar sua relevância através de questionamentos associados à degradação ambiental e à qualidade de vida da sociedade. Tendo-se em vista o grau de relevância do tema trabalhado ao qual engloba todos os aspectos, principalmente saúde pública e degradação do meio ambiente, torna-se necessário a discussão sobre a disposição final desses resíduos sólidos no município de Uiraúna-PB e o quanto os mesmos podem afetar caso não haja um descarte final adequado. Este trabalho procura analisar e evidenciar pontos que possam ser melhorados no que se diz respeito ao gerenciamento de resíduos sólidos no município visando um gerenciamento que possa beneficiar todos os envolvidos.

O trabalho em questão contou com a aplicação de questionário com 37 perguntas para a população do município de Uiraúna-PB, sendo que 4 questões eram direcionadas a traçar um perfil socioeconômico dos participantes, e as demais 33 voltadas para os indicadores de sustentabilidade. Com relação às questões referentes aos indicadores de sustentabilidade vinte foram consideradas como favoráveis e treze como desfavoráveis, porém é importante ressaltar que a maioria dos indicadores que foram destacados como favoráveis são referentes a perguntas de conhecimento e opinião sobre uma gestão de resíduos adequada e de como esses RSU poderiam afetar a população quando não acondicionados de forma adequada. Enquanto que as desfavoráveis estavam voltadas para questões mais relevantes como inexistência de local apropriado para o descarte final de resíduos, vazadouros a céu aberto próximo às residências, contaminação de populares através desses resíduos.

Feita a análise dos dados, os mesmos foram transformados em dados quantitativos, e dentro da margem proposta, somaram 20 pontos, permitindo considerar positiva a tendência no questionário. Desse modo pôde ser constatado que de fato a população sabe que o município necessita de melhorias no seu gerenciamento de resíduos, e um local para que haja sua disposição adequada, sendo a população favorável também a políticas públicas voltadas para essa questão.

Tendo-se em vista o grau de importância da problemática abordada, considerando o prejuízo ambiental que isso pode levar, considerando também todo aspecto do meio natural e isso engloba fauna, flora, solo, ar e água além da perca da qualidade de vida da população, foi possível chegar a algumas conclusões a respeito da problemática. $\mathrm{O}$ município em questão possui diversos problemas com relação ao seu gerenciamento de resíduos urbanos que puderam ser observados durante todo seu estudo, no qual destacou a inexistência de local adequado para o descarte de resíduos urbanos, vazadouro a céu aberto, próximos às residências de populares, possibilitando um alto risco de contaminação a moradores que moram próximos a esses locais.

Nesse contexto atual, a situação do município não se adequou a lei de Política Nacional dos Resíduos Sólidos (PNRS), dessa forma o indicador coleta de lixo e disposição final em vazadouros a céu aberto é considerado desfavorável à sustentabilidade. Dentro dessa perspectiva fica nítida a urgência que o município de Uiraúna-PB tem, para que haja mudanças em seu gerenciamento de resíduos sólidos urbanos, assim podemos evidenciar estratégias e métodos que possam minimizar os impactos provocados pelo mau gerenciamento, como também implantar políticas públicas voltadas para educação ambiental, introdução de projetos que visem a reeducação com relação ao consumo desses resíduos e orientação sobre a coleta seletiva, além da instalação de um aterro sanitário seguindo todas as normas e leis previstas na legislação, podendo haver a recuperação de áreas contaminadas e sua revitalização. Desse modo, só assim com o empenho de todos os envolvidos, órgãos responsáveis, atores sociais podem se traçar metas e desenvolver técnicas e ações a fim de resolver a problemática ou mitigar seus efeitos. 
Assim, o estudo em questão possibilitou uma análise detalhada do gerenciamento de resíduos sólidos urbanos no município, confirmando a hipótese inicial do estudo, onde de fato foi constatada a deficiência na gestão de resíduos sólidos no Município de Uiraúna, Estado da Paraíba.

\section{Referências}

Barbosa G.S. (2008) O desafio do desenvolvimento sustentável. Revista Visões, 1(4): 1-11.

Barros J.D.S., Chaves L.H.G. \& Farias S.A.R. (2014) Aspectos socioeconômicos da microbacia hidrográfica do Riacho Val Paraíso-PB. Revista de Desenvolvimento Regional, 19(1): 169-187. http://dx.doi.org/10.17058/redes.v19i1.3904

Bento F.F.L. (2020) Avaliação do gerenciamento de resíduos sólidos urbanos por meio de indicadores de sustentabilidade no município de Nazarezinho-PB. Monografia (Graduação em Ciências Biológicas). Universidade Federal de Campina Grande, Cajazeiras, Paraíba.

Bernardo M. \& Lima R.S. (2017) Planejamento e implantação de um programa de coleta seletiva: utilização de um sistema de informação geográfica na elaboração das rotas. Revista Brasileira de Gestão Urbana, 9(1): 385-395. http://dx.doi.org/10.1590/2175-3369.009.SUPL1.AO10

Berticelli R., Pandolfo A. \& Korf E.P. (2017) A gestão integrada de resíduos sólidos urbanos: perspectivas e desafios. Revista Gestão \& Sustentabilidade Ambiental, 5(2): 711-744. http://dx.doi.org/10.19177/rgsa.v5e22016711-744

Brasil (2010) Lei $\mathrm{n}^{0}$ 12.305, de 2 de agosto de 2010. Institui a Política Nacional de Resíduos Sólidos.

Cabral J.V.B., Oliveira F.H.P.C., Silva L.R.F., Silva V.V. \& Araújo W.J. (2015) Resíduos hospitalares: o papel da enfermagem no processo de saúde-doença. Revista Eletrônica Diálogos Acadêmicos, 8(1): 60-71.

Cafure V.A. \& Patriarcha-Graciolli S.R. (2015) Os resíduos de serviço de saúde e seus impactos ambientais: uma revisão bibliográfica. Interações, 16(2): 301-314. https://doi.org/10.1590/151870122015206

Camargo M.E., Motta M.E.V., Lunelli M.O. \& Severo E.A. (2009) Resíduos sólidos de serviço de saúde: um estudo sobre o gerenciamento. Scientia Plena, 5(7): 1-14.

Carvalho V.G. \& Estender A.C. (2017) Conscientização ambiental contribuindo para eliminar o desperdício e ampliar as ações a favor do meio ambiente. Revista Desafios, 4(2): 1-17. http://dx.doi.org/10.20873/uft.2359-3652.2017v4n2p150

Castro A.L.C. (2016) Aplicação de Indicadores de Sustentabilidade de Resíduos Sólidos Urbanos no município de Uberlândia-MG. Monografia (Graduação em Engenharia Ambiental). Universidade Federal de Uberlândia, Uberlândia, Minas gerais.

Cavalcanti M.C.C. (2013) Campanha de conscientização ambiental: prática discursiva e social na modernidade tardia. Tese (Programa de Pós-Graduação em Letras). Universidade Federal de Pernambuco, Recife, Pernambuco.

Ciquetti H.S. (2004) Lixo, resíduos sólidos e reciclagem: uma análise comparativa dos recursos didáticos. Educar em Revista, 23: 307-333. https://doi.org/10.1590/0104-4060.344

Conde T.T., Stachiw R. \& Ferreira E. (2014) Aterro sanitário como alternativa para preservação ambiental. Revista Brasileira de Ciências da Amazônia, 3(1): 69-80.

Correia V.M.S., Aquino M.D., Thomaz A.C.F. \& Correia M.L.V. (2018) Estudo de caso: aspectos e impactos perceptíveis na localização de lixões municipais utilizando a ferramenta MMACBETH. Revista DAE, 66(211): 35-49.

Costa F.M., Campos J.C., Fonseca F.V. \& Bila D.M. (2015) Tratamento de lixiviados de aterros de resíduos sólidos utilizando processos fenton e foto-fenton solar. Revista Ambiente e Água, 10(1): 107-116. https://doi.org/10.4136/ambi-agua.1483

Costa T.G.A., Iwata B.F., Castro C.P., Coelho J.V., Clementino G.E.D. \& Cunha L.M. (2016) Impactos ambientais de lixão a céu aberto no município de Cristalândia, Estado do Piauí, nordeste do Brasil. Revista Brasileira de Gestão Ambiental e Sustentabilidade, 3(4): 79-86. http://dx.doi.org/10.21438/rbgas.030408 
Cunha V. \& Caixeta Filho J.V. (2002) Gerenciamento da coleta de resíduos sólidos urbanos: estruturação e aplicação de modelo não-linear de programação por metas. Gestão e Produção, 9(2): 143-161. https://doi.org/10.1590/S0104-530X2002000200004

Ferreira M.S. \& Barros J.D.S. (2021) Avaliação do gerenciamento de resíduos sólidos através do Sistema de Indicadores de Sustentabilidade Pressão-Estado-Impacto-Reposta (PEIR) no Município de Uiraúna, Estado da Paraíba, Nordeste do Brasil. Revista Brasileira de Gestão Ambiental e Sustentabilidade, 8(18): 653-672. https://doi.org/10.21438/rbgas(2021)081843

Ferreira R.S., Souza B.R., Siqueira D.M., Silveira M.E.C.S., Gonçalves S.L. Santos W.F. \& Santiago Y.C. (2019) Áreas degradadas: técnicas de reflorestamento ambiental. Revista Cientifica Multidisciplinar Núcleo de Conhecimento, 11(4): 71-84. https://doi.org/10.32749/nu cleodoconhecimento.com.br/engenharia-ambiental/areas-degradadas

Giaccom-Ribeiro M.B. \& Mendes C.A.B. (2018) Avaliação de parâmetros na estimativa da geração de resíduos sólidos urbanos. Revista Brasileira de Planejamento de Desenvolvimento, 7(3): 422-443. https://doi.org/10.3895/rbpd.v7n3.8652

Gomes L.P., Kohl C.A., Souza C.L.L., Rempel N., Miranda L.A.S. \& Moraes C.A.M. (2015) Avaliação ambiental de aterros sanitário de resíduos sólidos urbanos procedidos ou não por unidades de compostagem. Engenharia Sanitária e Ambiental, 20(3): 449-462. https://doi.org/10.1590/S1413-41522015020000120751

Gouveia N. (2012) Resíduos sólidos urbanos: impactos socioambientais e perspectiva de manejo sustentável com inclusão social. Ciência \& Saúde Coletiva, 17(6): 1503-1510. https://doi.org/10.1590/S1413-81232012000600014

Klein F.B., Gonçalves-Dias S.L.F. \& Jaya M. (2018) Gestão de resíduos sólidos urbanos da bacia hidrográfica do alto Tietê: uma análise sobre o uso de TIC no acesso a informação governamental. Revista Brasileira de Gestão Urbana, 10(1): 140-153. https://doi.org/10.1590/2175-3369.010.001.AO10

Leite M.F. (2006) A taxa de coleta de resíduos sólidos domiciliares: uma análise crítica. Dissertação (Programa de Pós-Graduação em Engenharia civil). Universidade Federal de São Paulo, São Carlos, São Paulo.

Leite A.L. \& Barros J.D.S.B. (2019) Avaliação da sustentabilidade socioambiental no gerenciamento de resíduos sólidos no Município de São José de Piranhas, Estado da Paraíba, Nordeste do Brasil. Revista Brasileira de Gestão Ambiental e Sustentabilidade, 6(14): 713-731. https://doi.org/10.21438/rbgas.061407

Lima T.S. \& Barros J.D.S.B. (2019) Avaliação do gerenciamento de resíduos sólidos através do Sistema de Indicadores de Sustentabilidade Pressão-Estado-Impacto-Reposta (PEIR) no Município de Cachoeira dos Índios, Estado da Paraíba, Nordeste do Brasil. Revista Brasileira de Gestão Ambiental e Sustentabilidade, 6(14): 749-765. https://doi.org/10.21438/rbgas.061409

Mancini S.D., Ferraz L.J. \& Bizzo W.A. (2012) Resíduos sólidos (p. 346-374). In: Rosa A.H., Fraceto L.F., Moschini-Carlos V. Meio Ambiente e sustentabilidade. Porto Alegre: Bookman. 412 p.

Moreira R.S., Barros J.D.S., Silva J.L.A., Araujo J.T. \& Pordeus A.V. (2017) Sustentabilidade Socioambiental no gerenciamento de resíduos sólidos urbanos: estudo de caso com aplicação do modelo Pressão-Estado-Impacto-Resposta. Espacios, 38(58): 1-8.

Oliveira M.C.B.R. (2012) Gestão de resíduos plásticos pós-consumo para a reciclagem no Brasil. Dissertação (Programa de Pós-Graduação em Planejamento Energético). Universidade Federal do Rio de Janeiro, Rio de Janeiro.

Oliveira K.C., Santos R.M.S. \& Viana A.L. (2016) Geração de resíduos sólidos: a percepção da população em um bairro de cidade de Manaus, Amazonas. InterfacEHS, 11(1): 1-11.

Pereira S.S., Curi R.C. \& Curi W.F. (2018) Uso de indicadores na gestão dos resíduos sólidos urbanos: uma proposta metodológica de construção e análise para municípios e regiões. Engenharia Sanitária e Ambiental, 23(3): 471-483.

https://doi.org/10.1590/S1413-41522018162872 
Pordeus A.V., Barros J.D.S., Moreira R.S., Araújo J.T. \& Silva J.L.A. (2019) Aspectos socioeconômicos do Perímetro Irrigado Várzeas de Sousa (PIVAS) no Semiárido paraibano. Pesquisa e Ensino em Ciências Exatas e da Natureza, 3(2): 189-198. http://dx.doi.org/10.29215/pecen.v3i2.1275

Portela, M.O. \& Ribeiro, J.C.J. (2014) Aterros sanitários: aspectos gerais e destino final dos resíduos. Revista Direito Ambiental e Sociedade, 4(1): 115-134.

Prodanov C.C. \& Freitas E.C. (2013) Metodologia do trabalho científico: métodos e técnicas do trabalho acadêmico. Novo Hamburgo: Feevale. 276 p.

Querino L.A.L. \& Pereira J.P.I.G. (2016) Geração de resíduos sólidos: percepção da população de São Sebastião de lagoa de roça, Paraíba. Revista Monografias Ambientais, 15(1): 404-415. https://doi.org/10.5902/2236130819452

Rodrigues C.R.P. \& Menti M.M. (2016) Resíduos sólidos: gerenciamento e políticas públicas federais. Caderno do Programa de Pós-Graduação em Direito PPGDir/UFRGS, 11(3): 59-79. https://doi.org/10.22456/2317-8558.66487

Silva N.M. \& Nolêto T.M.S.J. (2004) Reflexões sobre lixo, cidadania e consciência ecológica. Revista Eletrônica do Curso de Geografia do Campus Avançado de Jataí-GO, 2: 1-14. https://doi.org/10.5216/rev.\%20geoambie.v0i2.25863

Siqueira M.M. \& Moraes M.S. (2009) Saúde coletiva, resíduos sólidos urbanos e os catadores de lixo. Ciência \& Saúde Coletiva, 14(16): 2115-2122. https://doi.org/10.1590/S1413-81232009000600018

Soares A.M., Barros J.D.S. \& Bezerra D.S. (2017) Aplicação do Sistema de Indicadores de Sustentabilidade Pressão-Estado-Impacto-Resposta (PEIR) no Município de Nazarezinho-PB: enfoque no estado dos resíduos sólidos. Revista Brasileira de Gestão Ambiental e Sustentabilidade, 4(8): 255-262. https://doi.org/10.21438/rbgas.040802

Sousa G.L.M., Ferreira V.T.O. \& Guimarães J.C. (2019) Lixão a céu aberto: implicações para o meio ambiente e para a sociedade. Revista Valore, 4: 367-376. https://doi.org/10.22408/reva402019377367-376

Souza M.C.B., Mello I.S. (2015). Resíduos sólidos: coleta seletiva estímulo para o aumento da reciclagem e melhoria de renda dos catadores. Revista Eletrônica Gestão \& Saúde, 6(3): 29592981.

Vasquez S.F., Barros J.D.S. \& Silva M.F.P. (2008) Alternativas à agricultura convencional. Revista Verde de Agroecologia e Desenvolvimento Sustentável, 3(3): 06-12.

Vicente A.R.P., Bertolini G.R.F. \& Ribeiro I. (2016) Recepção da população quanto aos indicadores de sustentabilidade de Curitiba: a cidade sustentável do planeta. Revista Gestão e Sustentabilidade Ambiental, 4(2): 254-272. http://dx.doi.org/10.19177/rgsa.v4e22015254-272

Vieira A.C.P. \& Garcia J.R. (2012) A gestão de resíduos sólidos domésticos no Brasil a par da experiência internacional. Revista Economia e Tecnologia, 8(4): 57-66.

Zanella L.C.H. (2013) Metodologia de pesquisa. Florianópolis: UFSC. 134 p. 